\title{
PARA UMA HISTÓRIA DA AVALIAÇÃO DA EDUCAÇÃO SUPERIOR BRASILEIRA: ANÁLISE DOS DOCUMENTOS DO PARU, CNRES, GERES E PAIUB ${ }^{1}$
}

\author{
Gladys Beatriz Barreyro* \\ José CARLOS RotheN**
}

Recebido em: 27/11/07

Avaliado em: 20/01/2008

\begin{abstract}
*Dra. em Educação. Professora da Universidade de São Paulo. GEPPHAES (Grupo de Estudos e Pesquisa em Política e História da Avaliação da Educação Superior). O texto é produto da pesquisa em desenvolvimento, "Avaliação e Regulação da Educação Superior brasileira: concepções e atores", realizada com financiamento da FAPESP). Email: gladysb@usp.br.

${ }^{* * *}$ Dr. em Educação. Professor do Mestrado em Educação Superior do UNITRI. GEPPHAES (Grupo de Estudos e Pesquisa em Política e História da Avaliação da Educação Superior). O texto é produto de pesquisa em desenvolvimento “Avaliação e Regulação da Educação Superior brasileira: história e políticas", realizada com financiamento da FAPEMIG. Email: jcrothen@bol.com.br. Site www.rothen.pro.br
\end{abstract}

"Con la historia de la educación buscamos comprender el presente. Sino, seríamos meros anticuarios".

Pablo Pineau.

Resumo: Com o Provão, em 1996, e depois com o SINAES, em 2004, a avaliação passou a ser um elemento central na política de educação superior brasileira. Apesar das influências dos modelos internacionais as duas principais concepções adotadas (a da avaliação com uma visão formativa/emancipatória e a de regulação/controle) foram delineadas pelos acadêmicos participantes de comissões governamentais do Ministério da Educação durante as décadas de 1980 e 1990. No artigo, analisam-se essas duas concepções e algumas das suas implicações nas políticas atuais. São considerados os documentos oficiais: "Programa de Avaliação da Reforma Universitária" (1983); "Relatório da Comissão Nacional de Avaliação do Ensino Superior" "Uma Nova Política para a Educação Superior Brasileira" (1985), "Relatório do Grupo Executivo para a Reformulação da Educação Superior" (1986). e "Programa de Avaliação Institucional das Universidades Brasileiras" (1993).

Palavras-Chave: Avaliação da educação superior. História da avaliação da educação superior. PARU. CNRES. PAIUB.

\author{
FOR A HISTORY OF BRAZILIAN HIGHER EDUCATION EVALUATION: \\ ANALYSIS OF PARU, CNRES, GERES AND PAIUB DOCUMENTS
}

\footnotetext{
Abstract: Evaluation became a central element in higher education policy in Brazil, first in 1996 with ENC-Provão and, then, in 2004, with SINAES. Despite the influences of international models,

1 A versão preliminar deste texto foi apresentada no VIII Congreso Iberoamericano de Historia de la Educación Latinoamerica, em Buenos Aires, com o título "História da Avaliação da Educação Superior no Brasil 1980-1992: Concepções e Atores”.
} 
the two main conceptions adopted (the formative and the regulatory evaluation) were outlined by the academics who participated in government commissions at the Ministry of Education, during 80 's and 90 's. In this paper, these two concepts and some of their implications in current policies are analyzed. The official documents "Evaluation Program of the University Reform" (1983); "A New Policy for the Brazilian Higher Education" (1985); "Report of the Executive Group for Higher Education Revision" (1986) and "Institutional Evaluation Program of the Brazilian Universities" (1993.) are considered.

Key words: Higher education evaluation. History of higher education evaluation. PARU. CNRES. PAIUB.

\section{Introdução}

Na segunda metade da década de 1990, começou um processo que iria instituir a avaliação como política regulatória na educação superior brasileira. Em 1996, foi implantada uma sistemática de avaliação baseada na realização de uma prova pelos formandos da graduação e que visava, principalmente, à constituição de um "quase-mercado" da Educação Superior. Alguns anos depois, em 2004, foi estabelecido um sistema nacional de avaliação, depois de árdua disputa sobre o modelo a ser adotado. Apesar das influências dos modelos internacionais, a concepção de educação superior e de avaliação presente nas políticas implantadas foi gestada por acadêmicos envolvidos com comissões governamentais inseridas no Ministério da Educação durante as décadas de 1980 e 1990.

Desse processo destacam-se quatro propostas de educação superior e de avaliação, que foram expressas nos seguintes documentos: "Programa de Avaliação da Reforma Universitária" (1983), o relatório da Comissão Nacional de Reformulação da Educação Superior "Uma Nova Política para a Educação Superior Brasileira" (1985), o "Relatório do Grupo Executivo para a Reformulação da Educação Superior" (1986) e o documento da Comissão Nacional de Avaliação do Ensino Superior "Programa de Avaliação Institucional das Universidades Brasileiras" (1993).

Essas propostas apresentaram entre si continuidades, similitudes, diferenças e confronto de posições. Dada a importância dessas e o papel relevante que os seus atores tiveram na época e viriam a ter, posteriormente, na criação de um sistema de educação superior e de um sistema de avaliação, o trabalho analisa as quatro propostas, identificando os pontos de aproximação e de divergências entre elas.

Na construção deste texto, far-se-á a exposição da estrutura dos princípios norteadores dos documentos e a análise dos aspectos principais. Nas consi- 
derações finais, são realizadas comparações entre eles, levando em conta sua influência posterior nas políticas para esse nível de ensino.

\section{Programa de Avaliação da Reforma Universitária (PARU)}

O Programa de Avaliação da Reforma Universitária (PARU) foi desenvolvido no final do governo militar, em junho de 1983, por iniciativa do Conselho Federal de Educação (CFE) ${ }^{2}$, como desdobramento de discussões internas do Conselho decorrentes das greves mantidas nas universidades federais (CUNHA, 1997) 3 . A experiência da Comissão de Aperfeiçoamento do Pessoal Superior (CAPES) na avaliação da pós-graduação do país levou Edson Machado de Souza, então diretor-geral da CAPES e membro do CFE, a propor o PARU (CUNHA, 1997). Para tanto, foi designado um Grupo gestor composto pelo próprio Souza, como coordenador, e acompanhado por Sérgio Costa Ribeiro (coordenador técnico), Isaura Belloni Schmidt (coordenadora técnica substituta), Maria Stela Grosi Porto, Maria Umbelina Caiafa Salgado, Mariza Veloso Motta Santos, Mônica Muños Bargas e Orlando Pilatti, que, segundo o documento, eram "pesquisadores com experiência em análise e acompanhamento de projetos" (GRUPO GESTOR DA PESQUISA, 1983, p. 83). Os últimos cinco integrantes eram técnicos do Ministério da Educação (CUNHA, 1997, p. 23).

Para a análise do Programa de Avaliação da Reforma Universitária (PARU), tomou-se como fonte primária o texto "Programa de Avaliação da Reforma Universitária”, de autoria de Grupo Gestor da Pesquisa (1983), publicado na revista Educação Brasileira, editada pelo Conselho de Reitores das Universidades Brasileiras ${ }^{4}$.

Segundo o Grupo Gestor, o PARU tinha como objetivo conhecer as condições reais nas quais se realizavam as atividades de produção e disseminação do conhecimento do sistema de educação superior. Para isso, considerava necessário diagnosticar a situação desse momento de forma a "avaliar o sistema de educação superior, em seu conjunto, nele incluidas as universidades e instituições isoladas, públicas e privadas" (p. 84). O PARU pretendia realizar “investigação sistemática da realidade”, por meio de estudos, pesquisas e de-

2 O Conselho Federal de Educação - instituído em 1962 e substituído em 1994 pelo Conselho Nacional de Educação - foi um órgão colegiado vinculado ao Ministério da Educação que exercia funções regulatórias 3 O Conselho Federal de Educação organizou dois encontros em 1981 (Colóquio sobre o Ensino Superior no Brasil e Seminário sobre indicadores de qualidade do ensino superior), que foram publicados, em 1982, no volume A propósito da qualidade do ensino superior no Brasil.

4 Normalmente, os artigos que apresentam a história da avaliação da educação no Brasil fazem referência ao PARU, contudo não citam as fontes completas utilizadas para análise (CUNHA, 1997; BELLONI, 1989; AMORIM, 1992). Na falta de documentos oficiais, optou-se por utilizar o texto de autoria do Grupo Gestor. 
bates, tanto da implementação das propostas da reforma universitária de 1968 quanto das particularidades institucionais e regionais.

Para a concreção dos seus objetivos, considerava necessária a participação, especialmente, da comunidade acadêmica, realizando "um processo de reflexão sobre sua própria prática" e de outros setores externos às instituições, sobretudo, na expressão de demandas e expectativas quanto ao papel da universidade e sua organização. Segundo afirmado, o próprio PARU foi elaborado mediante consulta a "segmentos representativos da comunidade acadêmica" (p. 85)

Foram determinadas duas áreas para realização dos estudos:

a) Gestão das Instituições de Educação Superior (IES): seriam tratados assuntos como: Poder e tomada de decisão, Administração Acadêmica, Administração Financeira e Financiamento e Política de Pessoal.

b) Processo de produção e disseminação do conhecimento: seriam estudados: o Ensino e a Pesquisa nas IES e a Interação entre IES e comunidade (p. 86).

A proposta do PARU destacava a diferença entre a norma ideal sancionada e a operacionalização desta na realidade. Propunha questionar o conhecimento produzido, levando em conta o contexto sócio-econômico no qual estaria inserida a IES. Assim, pretendia desvendar como estariam sendo concretizados os objetivos de cada IES, bem como sua articulação com o uso de recursos, com as determinações externas e as relações políticas internas. Outros assuntos que seriam indagados:

- a qualidade do ensino, a ênfase dada à formação do cidadão e do profissional;

- a relação da pesquisa com o ensino, a importância dada à pesquisa básica $\mathrm{e}$ aplicada, bem como sua vinculação às necessidades sociais e empresariais;

- a extensão e a prestação de serviços e a assistência comunitária e sua relação com as atividades de ensino e pesquisa; e

- as atividades administrativas e sua influência no ensino e a pesquisa, os recursos materiais, assim como as representações e aspirações do público acadêmico e não acadêmico e a dimensão política que perpassa por todas essas atividades.

A pesquisa constava de duas fases: a primeira, um estudo base, com o intuito de coletar informações fundamentais sobre as IES, que seria realizado por amostra mediante a aplicação de um instrumento-padrão, e a segunda, estudos especificos ou estudos de casos, que aprofundariam o estado de conhecimento sobre um assunto, experiências relevantes, análises específicas, etc. O estudo 
base pretendia coletar dados que permitissem a comparabilidade entre instituições.

O PARU, talvez pela sua ligação com a CAPES, que congrega a pós-graduação e grande parte da pesquisa do país, e pelo perfil dos integrantes do seu Grupo gestor, adquiriu a forma de um projeto de pesquisa sobre o estado da educação superior no país. Isso imprimiu a ele caráter de busca, indagação, investigação que fundamentaria ações futuras, o que o diferencia de documentos afirmativos e propositivos posteriores. Nessa linha, eram convidados a participar grupos interessados de pesquisadores das IES (PARU, 1983).

O Grupo Gestor do PARU considerou as instituições como unidade de análise e destacou o papel da avaliação. A avaliação, nesse Programa, foi entendida como uma forma de conhecimento sobre a realidade, como uma metodologia de pesquisa que permitiria não só obter os dados, mas também permitia fazer "uma reflexão sobre a prática". Assim, o PARU, com a finalidade de realizar uma pesquisa de avaliação sistêmica, recorreu à "avaliação institucional" e considerou à "avaliação interna" como procedimento privilegiado. Para isso, propôs a participação da comunidade na realização de auto-avaliação. Nesse sentido, o PARU, foi o precursor das experiências de avaliação posteriores no país (PAIUB, SINAES-CEA) inaugurando a concepção de avaliação formativa e emancipatória, pois, conforme Cunha (1997, p. 23), "'apesar de originário na CAPES (cujo sistema de avaliação tinha viés quantitativista), o enfoque da pesquisa era avesso ao tecnicismo dominante no Ministério da Educação”.

Outra das heranças deixadas pelo Programa foi a sua preocupação com a avaliação dos resultados da Gestão das Instituições de Educação Superior. No contexto do PARU, a ênfase nos processos de gestão não significou a desvalorização dos procedimentos acadêmicos, mas na incorporação dessa dimensão na análise institucional.

O PARU não chegou a apresentar seus resultados, pois "foi desativado um ano depois de começado, devido a disputas internas ao próprio Ministério da Educação, em torno de quem competia fazer a avaliação da Reforma Universitária" (CUNHA, 1997, p. 23). Na época a coordenadora técnica substituta Isaura Belloni previa (1989, p. 62):

Depois de três anos de desenvolvimento, a pesquisa de maior porte já desenvolvida neste país acerca de educação superior está com escassa possibilidade de chegar a termo, para concretizar seu objetivo de servir de subsídio à tomada de decisão e formulação de políticas. A destituição do Grupo [Gestor da Pesquisa], decidida pelo próprio 
coordenador e por dirigentes da SESu, foi justificada sob o argumento de 'pouca produtividade e não colaboração com as necessidades' da SESu, e em particular do Grupo Executivo da Reforma da Educação Superior (GERES) cujos trabalhos encerraram-se em princípio de setembro de 1986.

O PARU deixava inconclusos a coleta de dados e os estudos institucionais iniciados, que tinham contado, inclusive, com financiamento público, pois diferentes concepções de educação superior começavam a aparecer. Os membros do PARU (Edson Machado de Souza, Isaura Belloni, Orlando Pilatti e Sergio Costa Ribeiro) comporiam, posteriormente, comissões ministeriais e participariam da elaboração ou execução de outras experiências de avaliação da educação superior no país.

\section{Uma nova política para a educação superior brasileira}

A Comissão Nacional Para Reformulação da Educação Superior foi instituída pelo Decreto 91.177, de 29 de março de 1985, visando à reformulação da educação superior, no marco da re-democratização do país, com a instauração da Nova República. O governo do presidente José Sarney ${ }^{5}$ atendeu as demandas de entidades docentes e instituiu uma comissão composta por 24 membros $^{6}$, heterogênea quanto à formação, atuação e posições públicas assumidas.

5 Em 1984, o Congresso brasileiro elegeu para a presidência da república Tancredo Neves. Na véspera da sua posse, Neves foi internado com sérios problemas de saúde e posteriormente veio a falecer. Por arranjo político, visando evitar uma instabilidade política/social em um momento delicado de transição do regime militar para o estado democrático, o vice-presidente José Sarney assumiu o cargo, em 1985, e passou a exercer a presidência. Durante todo o governo, Sarney, em documentos oficiais, era apresentado como presidente em exercício e não como o Presidente da República.

6 Eram eles: Caio T.S P. de Vasconcelos, Presidente, membro do Conselho Federal de Educação, Amílcar Tupiassu, professor da Universidade Federal do Pará, Bolívar Lamounier, professor da USP e PUC-SP, Carlos Nelson Coutinho, Prof. das Faculdades Integradas Benett, Edmar Lisboa Bacha, Professor na PUC_RJ e presidente do IBGE, Eduardo De Lamonica Freira, Reitor da UFMT, Fernando J.Lessa Samento, Pró-reitor da UFBA, Francisco Javier Alfaya, estudante; Guiomar Namo de Mello, Professora na PUC_SP e Secretária de Educação do Município de SP, Haroldo Tavares, Empresário, ex-Diretor da Escola de Engenharia da UEMaranhão, Jair Pereira dos Santos, Ex Diretor do DIEESE, sindicalista; José Leite Lopes, Professor na UFRJ e presidente do Centro Brasileiro de Pesquisas Físicas; José Arthur Gianotti, Professor da USP e presidente do CEBRAP; Dom Lourenço de Almeida Prado, Prof. de Filosofia e Teologia no Mosteiro de São Bento, RJ, Luiz Eduardo Wanderley, Reitor da PUC de São Paulo, Marly M.M. Silva Araújo, Secretaria de Educação de MG, Paulo da Silveira Rosas, Professor da UFPe, Roberto Cardoso de Oliveira, Professor na UNICAMP, Romeu Ritter dos Reis, Presidente da Sociedade de Educação Ritter dos Reis, de Porto Alegre. Simon Schwartzmann (relator), Professor e diretor do IUPERJ, Ubiratan Borges de Macedo, membro do Conselho Federal da Cultura e professor na UFPR. Posteriormente, foi nomeado José Eduardo Campos de Oliveira Faria, assessor da Presidência do Banco Itaú (ROSAS, 1985). 
Segundo os dizeres um dos seus integrantes, Paulo Rosas (1985, p. 92) "Embora fosse possível admitir um relativo equilíbrio entre as tendências mais progressistas e mais conservadoras, entendo que predominou numericamente um comportamento "liberal-elitista", o qual beneficiou quase sempre a corrente mais conservadora da Comissão."

O resultado do trabalho da Comissão materializou-se no Relatório intitulado "uma nova política para a educação superior brasileira", que teve como relator Simon Schwartzman. Na introdução do relatório, a Comissão afirmou que não existiriam fórmulas mágicas e, que conseqüentemente, a simples elaboração de uma nova lei não resolveria os problemas da educação superior. Evidente no documento, já no seu título, que seria necessária a criação de uma nova política e não de uma nova lei.

$\mathrm{Na}$ apresentação do texto e nas declarações de votos, foi explicitado que o relatório apresentava o consenso conseguido, apesar das divergências dos membros da Comissão sobre diversos assuntos. Na interpretação de CUNHA (1997, p. 24): Tamanha diversidade propiciou que o produto da comissão fosse um conjunto de textos a propósito de questões desencontradas, base de um relatório conforme as diretrizes implícitas do ministério, seguido de votos em separado.

O documento constitui-se de cinco partes: 1) a apresentação dos princípios norteadores da proposta; 2) as idéias gerais de reformulação; 3 ) as sugestões de ações pontuais para operacionalização das idéias gerais; 4) a declaração de voto de alguns membros da Comissão sobre aspectos pontuais de divergência com o relatório; 5) a proposta de algumas ações de emergência.

Em linhas gerais, defendeu-se, no documento, que, para a superação da crise da universidade brasileira, se deveria aumentar, significativamente, a autonomia universitária que seria acompanhada por um processo externo de avaliação baseado na valorização de mérito acadêmico.

$\mathrm{Na}$ apresentação das idéias do documento, são ressaltados os princípios norteadores, a proposta de reformulação do Conselho Federal de Educação, a relação entre autonomia e avaliação e a idéia da criação de um sistema de acreditação.

\subsection{Os princípios norteadores}

A comissão dividiu os princípios norteadores em sete:

a) Responsabilidade do poder público. Neste ponto, a Comissão defendia o princípio de que seria de responsabilidade do Poder Público financiar as pesqui- 
sas mais significativas, como apoiar financeiramente instituições particulares que realizassem atividades socialmente relevantes, e, finalmente, zelar pela qualidade do sistema. Portanto, competiria ao poder público financiar e zelar pela qualidade, mas não necessariamente realizar as atividades. É importante ressaltar que, apesar de o documento citar a importância da iniciativa privada, é muito forte a idéia de que o oferecimento da educação superior seria de responsabilidade do poder público.

b) Adequação à realidade do País. O ensino superior deveria voltar-se duplamente para o país, primeiro, em oferecer uma formação profissional que permitisse os egressos a se adaptarem a um mercado de trabalho em constante mudança. Segundo, com a criação de mecanismos de transferência para o meio social e econômico do conhecimento oriundo da pesquisa efetivada no meio acadêmico.

c) Diversidade e Pluralidade. Segundo a Comissão, a opção da Reforma Universitária, de 1968 de adotar o modelo de universidade para todo o sistema teria sido equivocada. Assim, dever-se-ia assegurar liberdade para que as Instituições assumissem modelos organizacionais e institucionais que fossem mais adequados para a realização dos objetivos e da vocação própria de cada Instituição ${ }^{7}$

d) Autonomia e democracia interna. O princípio da autonomia destaca-se entre os outros apontados pela Comissão, pois é a referência para toda a argumentação e a estruturação do documento. Ela foi definida como a "liberdade para que as universidades decidam internamente sobre as pesquisas que realizam, os curriculos de seus cursos, seus sistemas administrativos e organizacionais e à gestão de seus recursos" (COMISSÃO NACIONAL, 1985). A Comissão enfatiza que a autonomia não seria uma prerrogativa da cúpula da Universidade, mas, sim, de todas as unidades, para tanto seria necessária uma organização democrática.

A autonomia não teria um fim em si mesma, mas, sim, seria uma exigência para que o ensino superior cumprisse a sua missão. Dessa forma, a prerrogativa da autonomia supõe uma contrapartida em desempenho. Em outras palavras, para que ocorra tanto a formação profissional, como a realização de pesquisas com qualidade seria necessária a autonomia da universidade, assim, dada a au-

7 Essa proposta de diversificação de modelos institucionais viria a ser implementada durante o primeiro governo de Fernando Henrique Cardoso. O documento é a gênese dessa idéia (CUNHA, 1997). 
tonomia, a universidade deveria retribuir com uma performance que atendesse às demandas sociais.

e) Democratização do acesso dar-se-ia em dois sentidos, primeiro, com a melhoria da educação de primeiro e segundo graus; segundo, pela criação de outras modalidades de ensino, ao invés da expansão indiscriminada de um sistema constituído exclusivamente nos moldes acadêmicos tradicionais.

f) Valorização do desempenho. A Comissão compreendia que o controle sobre as instituições resumia-se aos aspectos formais e burocráticos, e haveria a necessidade de substitú́-los por mecanismos que tivessem em conta o mérito do trabalho desenvolvido pelas instituições.

g) Eliminação dos aspectos corporativos e cartoriais. A comissão propunha a diminuição da ingerência dos Conselhos Profissionais que regulamentam, no Brasil, diversas profissões. Segundo o diagnóstico da Comissão, os Conselhos dificultavam a reformulação dos currículos.

\subsection{A função do Conselho Federal de Educação (CFE)}

A Comissão avaliava que o CFE tinha perdido a sua real função de responsabilizar-se pelo "desempenho qualitativo do sistema de ensino em todos os graus". Tendência essa que teria sido gerada pela grande quantidade de processos casuísticos que o teria sobrecarregado de atividades. A Comissão propôs a reformulação do CFE, transferindo as suas atribuições casuísticas para o Ministério e as Universidades. A função do CFE seria a de realizar a avaliação por meio dos pares da Educação Superior.

Dessa forma, apesar de não ter sido encaminhada a proposta de reformulação do CFE, o documento introduzia pela primeira vez, a idéia de um órgão responsável pela avaliação - ou seja, uma "agência de avaliação" - e da disseminação para todo o sistema da metodologia de avaliação por pares utilizados pela Coordenação de Aperfeiçoamento de Pessoal de- Nível Superior (CAPES) na avaliação da pós-graduação brasileira, assuntos que, posteriormente, fizeram parte dos debates sobre avaliação.

No campo da ciência, a avaliação do trabalho dos cientistas por pares - fomentada por agências de financiamentos e comitês científicos - é o principal mecanismo para garantir a validade dos conhecimentos produzidos. De maneira

8 Apesar da idéia expressa no documento seja de criação de uma "agência de avaliação", o termo não foi utilizado. 
análoga, o trabalho dos pares - promovido pelo CFE - seria o julgamento do desempenho institucional, que levaria a justificar a autonomia.

Decorrente das atividades de avaliação, seria de responsabilidade do CFE fazer o reconhecimento do status universitário que garantiria a autonomia. Ainda, seria prerrogativa do Conselho ter voz ativa na política de financiamento público do ensino superior.

\subsection{Autonomia e avaliação}

A autonomia, como apresentado acima, seria uma concessão da sociedade em troca de altos padrões de qualidade no desempenho institucional. A sociedade, que financia a Universidade, teria o direito de exigir a prestação de contas da aplicação dos recursos e do desenvolvimento do ensino e da pesquisa.

A autonomia deveria ser ampliada no sentido de permitir que as Instituições fizessem a própria gestão financeira. Os recursos seriam repassados globalmente, e as Instituições fariam a distribuição interna desses conforme as prioridades institucionais. Dentro de uma visão meritocrática, a definição dos recursos que a Instituição receberia estaria vinculada ao resultado das avaliações promovidas pelo Conselho Federal de Educação.

A Comissão levantava duas questões que a avaliação das IES poderia acarretar: a) o controle social não iria ferir a autonomia universitária? b) quem teria a legitimidade para realizar esse controle? Para a primeira questão, a Comissão deu uma resposta evasiva, a saber, a autonomia não significaria que o Estado e a Sociedade pudessem isentar-se de participar do processo educacional e que seria importante a participação exógena. De certa forma, a Comissão deu como solução para o problema o próprio fato que gerou a dificuldade.

Em relação à segunda questão, sem sinalizar para uma resposta categórica, a Comissão sugeriu que a avaliação pela comunidade científica e acadêmica é que seria a mais ampla e legitima. No sentido de apontar para a solução sem a propor definitivamente, a Comissão, levantou os vários agentes que poderiam realizar a avaliação, a saber: a) auto-avaliação, b) agentes governamentais, c) avaliação pela comunidade profissional, d) avaliação por agências independentes. Após explicitar de forma sumária as vantagens e desvantagens de cada uma das opções, a Comissão concluiu que todas elas eram parciais e poderiam complementar-se. Finalmente, que caberia ao CFE, "a agência de avaliação", iniciar e conduzir o debate sobre a implantação da avaliação. Além da discussão sobre quem a realizaria no relatório da Comissão Nacional, foi apresentada uma lista de diversos instrumentos de avaliação da educação superior. 


\subsection{Acreditação}

Para o controle do funcionamento das instituições isoladas, a Comissão propôs a criação de um sistema de acreditação. Foram visualizadas duas possibilidades: a) Para funcionarem, as faculdades isoladas deveriam passar por um processo de acreditação pelas Universidades próximas. Assim, as Universidades, ao supervisionarem o trabalho dessas instituições teriam a condição de garantir a qualidade dos diplomas emitidos por elas; $b$ ) As instituições isoladas poderiam formar redes por áreas de conhecimento com abrangência nacional ou regional e estariam sujeitas à supervisão e à acreditação por órgãos normativos.

Apesar de a Comissão não usar o termo acreditação para as Universidades, é possível assegurar que essa idéia estaria presente na proposta de que o status de Universidade fosse concedido pelo Conselho Federal de Educação, após processo de avaliação da instituição. prática semelhante a um processo de acreditação.

\subsection{A lógica do documento}

Em síntese, a Comissão Nacional compreendia que a contrapartida da autonomia universitária seria o desempenho das instituições. O controle do desempenho se daria pela avaliação efetivada pelos pares, e, a partir desta, seria criado um sistema meritrocrático que nortearia o financiamento estatal da educação superior.

\section{GERES: Grupo Executivo para a Reformulação da Educação Superior}

O "Grupo Executivo da Reforma da Educação Superior" (GERES) foi criado como grupo interno do $\mathrm{MEC}^{9}$ (CARDOSO, 1989, p. 113). Foi constituído por cinco pessoas que exerciam funções no âmbito do Ministério da Educação ${ }^{10}$. Como está explícito no próprio nome do Grupo, ele tinha a função executiva de elaborar uma proposta de Reforma Universitária. O ponto de partida adotado foi o relatório final da Comissão Nacional de Reformulação da Educação Superior.

9 Portaria $\mathrm{n}^{\circ} 100$ de 6 de fevereiro de 1986, e instalado pela Portaria $\mathrm{n}^{\circ} 170$, de 3 de março de 1986

10 Segundo Schwartzman, eram eles, Antônio Octávio Cintra e Getúlio Carvalho, secretários gerais adjuntos do Ministério da Educação; Sérgio Costa Ribeiro, ex-coordenador técnico do Programa de Avaliação da Reforma Universitária (PARU); Edson Machado de Souza, diretor da Capes e ex-coordenador do PARU; e Paulo Elpídio Menezes Neto, Secretário de Educação Superior. 
A vinculação entre os dois documentos fica evidente no artigo publicado em 1988, em inglês, na "Higher Education" (Universidade da Califórnia)" ${ }^{11}$, por Simon Schwartzman, relator da Comissão. No texto, Schwartzman lamentava que o resultado do trabalho do GERES havia sido engavetado sem ser discutido e votado no Congresso Nacional. Segundo ele, o GERES recuperou o documento da Comissão para a elaboração de sua proposta.

O resultado do trabalho do GERES foi apresentado em um relatório que constava de um texto introdutório, dois anexos e dois anteprojetos de lei. No texto introdutório, expõem-se as conclusões do GERES, sempre fazendo a comparação entre as suas idéias e as defendidas pela Comissão. No primeiro anexo, encontra-se uma lista de execução das "medidas pertinentes" recomendadas pela comissão: a inclusão desse anexo transmite a impressão de que o GERES desejaria afirmar que o seu trabalho não contrariava o princípio defendido pela Comissão de que, mais de que uma nova lei, o país precisaria de uma nova política. No segundo anexo, tem-se a lista das entidades e pessoas que ofereceram sugestões ao Grupo ${ }^{12}$. O primeiro anteprojeto é de reformulação das Universidades Federais e o segundo de reformulação das funções do Conselho Federal de Educação.

O anteprojeto de lei de reformulação das IES federais foi divulgado em outubro de 1986, no contexto de greve de funcionários das IES e de ameaça de greve de professores. Segundo Cunha (1997, p. 26), o projeto foi criticado pelos professores, funcionários e estudantes, temendo que "a dotação global pudesse levar à desobrigação do governo para com o suprimento de recursos" e porque

11 Nessa pesquisa, usou-se a versão em português disponibilizada no site pessoal de Schwartzman.

12 Segundo o documento, as seguintes entidades ofereceram contribuições: Comissão da Academia Brasileira de ciências, Sociedade Brasileira de Matemática, Sociedade Brasileira de Física, Associação dos Docentes e Associação Nacional de Docentes do Ensino Superior, Associação Brasileira de Mantenedores, União Nacional dos Estudantes, Instituto dos Advogados Brasileiros, Escola Paulista de Medicina, DEMES/RS, DEMEC/GO e DEMEC/DF, Conselho Estadual de Educação de Alagoas, Fundação educacional Severino Sombra, Coordenação do Mestrado em Matemática da Universidade Federal do Ceará, Pontifícia Universidade Católica do Paraná, Universidade de Ijuí, Universidade Federal de Santa Catarina, Associação dos Professores da Universidade Federal do Paraná, Comissão da Universidade Braz Cubas. As seguintes pessoas ofereceram contribuições individuais: João Amílcar Salgado (UFMG), Sofia Lerche Vieira (UFC), José Nastri Filho (SESu/MEC), Mário Falcão Filho (SP), Philomeno J. da Costa (SP), Juliano F. Marin Filho (RS), Hortêncio Deconto (PR), João Lucas Marques Barbosa (UFC), Silvo Coelho dos Santos (UFSC). Também ocorreram consultas orais; a) na fase preliminar: os professores Fábio Wanderley Reis e José Eduardo Faria na fase preliminar do trabalho; b) sobre financiamento os professores Jacques Velloso, Alberto Mello e Souza e.o Dr. Rubens Queiroz; c) sobre credenciamento e funcionamento de instituições: Valnir Chagas, Rui Camargo Vieira e Ernesto Ahrens; d) ordenamento jurídico da educação superior: os professores Armando Dias Mendes, Rubens Maciel, José Ernesto Ballstaedt, Márcio Quintão Moreno, Carlos Roberto Martins Rodrigues e o Dr. Guido Ivan de Carvalho. 
"as entidades de professores temiam a perda de força política se tivessem que orientar suas reivindicações para dentro de cada universidade". O presidente da República retirou o anteprojeto do Congresso Nacional, permanecendo, as idéias aí presentes, como orientação da política geral do governo.

É interessante observar que o relatório do GERES é freqüentemente citado como instaurador da visão de regulação e controle da educação superior em vez do documento da Comissão. Entre outras, podem-se apontar as seguintes explicações para esse fato: a maior homogeneidade intelectual entre os membros do Grupo se comparado com a Comissão; o documento sistematizava os princípios adotados por essa visão, o fato de os anteprojetos terem sido divulgados durante uma greve e o apelo que a elaboração de uma proposta de reforma universitária via legislação tem na tradição brasileira.

\subsection{Os princípios do documento}

O GERES optou em restringir a sua proposta de reformulação da legislação pertinente à Educação Superior as Instituições públicas. Essa opção foi justificada com o fato de que as diversas propostas da Comissão Nacional teriam inúmeras implicações e que elas mereceriam maior discussão ${ }^{13}$. Outro argumento em favor dessa opção, e que deve ser ressaltado, é que a GERES compreendia que a estrutura das instituições públicas prevista pela Reforma Universitária de 1968 restringia a sua autonomia e diminuía o potencial de desempenho. Nessa linha de justificativa, o objetivo explicitado no documento do GERES seria elaborar uma proposta que aumentasse a eficiência das Instituições Federais.

O GERES retomou o fio condutor do documento da Comissão Nacional para a Reformulação da Educação Superior "Uma nova política para a educação superior brasileira", a saber, o aumento da autonomia universitária e a avaliação da responsabilidade social mediante processos públicos com critérios estabelecidos pela própria comunidade acadêmica.

A idéia do binômio autonomia/avaliação referendada pela comunidade acadêmica seria um dos pontos nevrálgicos da argumentação. O controle das Instituições não seria mais burocrático e ritualista e passaria a ser realizado pelos processos de avaliação institucional, deixando de verificar o cumprimento da legislação e averiguando o desempenho institucional.

13 Como exemplo das diversas dificuldades, o GERES citou a proposta da Comissão em acabar com o currículo mínimo, a sua adoção poderia passar para os Conselhos Profissionais a decisão de quem seria capaz de exercer as atividades profissionais reguladas por elas, assim, os diplomas universitários não garantiriam a habilitação nas profissões regulamentadas. 
Outro principio caro ao Grupo era de que o modelo, implantado pela Reforma de 1968, de associação entre o ensino e a pesquisa teria sido equivocado pelo fato de que a pesquisa seria um fator estranho à tradição do ensino brasileiro. Nessa linha de raciocínio, compreendia que, na realidade, existiria mais de um tipo de instituição de educação superior, e cada uma atenderia principalmente a uma função específica: a formação profissional ou a realização de pesquisa. Além dessa flexibilização, no documento, propôs-se a superação da idéia de que a universidade deveria abranger todos os campos do saber, portanto, poderiam existir universidades por áreas do saber.

O GERES compreendia que o que definiria a universidade não seria nem a pesquisa e nem a universalidade dos campos do saber, mas, sim, a sua autonomia didática, administrativa e financeira. O GERES propôs que estabelecimentos isolados de excelência poderiam gozar da autonomia, desde que tivessem reconhecido o seu status universitário. A proposta do GERES ocorreu em um círculo vicioso, pois caracterizava a universidade como uma instituição autônoma e, ao mesmo tempo, propunha que se fosse atribuída a outras instituições a autonomia, desde que tivessem o status universitário, ou seja, é universidade porque é autônoma e é autônoma porque é universidade.

\subsection{Avaliação e Financiamento}

Sem uma análise mais profunda, o GERES (1986, p. 8) apontou que o financiamento e a regulação do sistema são interligados. Eles compreendiam que, quando os recursos tivessem a sua origem no "sucesso" do produto, o sistema seria auto-regulado, contudo o mesmo não ocorreria quando os recursos proviessem do poder público. Sem usar o termo "mercado", a idéia presente é de que o mercado avalia o desempenho de quem "vende" um produto. Como o financiamento das instituições públicas não ocorre pela venda do produto, seriam necessários a avaliação e o controle do seu desempenho pelo Estado.

Ainda na mesma linha de raciocínio da Comissão Nacional de Reformulação da Educação Superior, o GERES defendia que deveria ser assegurado o recurso mínimo para a sobrevivência das Instituições federais, mas parte do financiamento das atividades deveria estar vinculada aos resultados da avaliação de desempenho.

\subsection{O Conselho Federal de Educação e a avaliação}

Diferentemente da Comissão, o GERES, embora concordasse que o Conselho Federal de Educação não deveria ocupar-se de atividades casuísticas, 
compreendia que o Conselho não poderia tornar-se uma agência de avaliação. Essa posição justifica-se, primeiro, porque haveria, na estrutura do sistema educacional, a necessidade de um órgão colegiado com poder deliberativo que mantivesse a unidade do sistema e criasse normas para os órgãos federais; segundo, que esse órgão colegiado não teria como realizar uma atividade sistemática como os processos de avaliação exigiriam.

Em relação aos procedimentos de acreditação, que, de certa forma, substituiriam a ação do CFE no documento "uma nova política para a educação superior brasileira", não foram tratados pelo GERES, a única menção é a negação de que as faculdades isoladas seriam "tuteladas", "acreditadas" pelas universidades.

Dentro do desenho estabelecido pelo GERES, a avaliação seria realizada pela Secretária da Educação Superior no âmbito do Ministério da Educação. Os resultados das avaliações seriam subsídios para o Conselho na sua ação normativa. Desta forma, o Conselho não faria a avaliação, mas seria usuário dos seus resultados;

\subsection{A lógica do documento}

A GERES compreendia que o sistema deveria ser flexibilizado, tanto nos seus objetivos (formação profissional e/ou pesquisa) como na sua estrutura organizacional, abandonando a idéia presente da Reforma Universitária de que o modelo único seria a universidade.

A avaliação, na visão do GERES, teria a função primordial de controlar a qualidade do desempenho da Educação Superior, especialmente a pública. No caso do setor privado, o próprio mercado faria a regulação, pois esse setor depende do sucesso do seu produto para obter os recursos para a sua manutenção e expansão. Assim nessa lógica, o financiamento da educação superior cumpriria, para o setor público, o mesmo papel que o mercado tem em relação ao privado.

\section{PAIUB}

Em 1993, no âmbito do Ministério da Educação foi criada, pela Portaria 130 da Secretaria de Educação Superior (SESu), a Comissão Nacional de Avaliação das Universidades Brasileiras, com o intuito de "estabelecer diretrizes e viabilizar a implementação do processo de avaliação institucional nas universidades brasileiras" (art.1). 
Essa Comissão ${ }^{14}$, coordenada pela SESu, diferentemente das anteriormente analisadas, compostas por "notáveis", reuniu entidades representativas da educação superior.

O primeiro resultado do trabalho da Comissão Nacional de Avaliação foi o "Documento Básico - Avaliação da Universidade Brasileira: uma proposta nacional". Estruturalmente, o documento foi dividido em duas partes: a primeira, com as referências teóricas sobre a avaliação da educação superior; a segunda, com as orientações para a implantação da avaliação.

\subsection{Os objetivos da avaliação}

O documento tem, em seu início, a apresentação da justificativa para a realização da avaliação das instituições. A Comissão expressou o entendimento de que a avaliação atenderia a uma tripla exigência a que as universidades contemporâneas estariam submetidas.

a) um processo contínuo de aperfeiçoamento do desempenho acadêmico;

b) uma ferramenta para o planejamento e gestão universitária;

c) um processo sistemático de prestação de contas à sociedade. (COMISSÂO NACIONAL, 1993).

De certa forma, essas exigências aproximam-se do campo discursivo dos documentos anteriores. A idéia da avaliação como ferramenta de gestão e planejamento é um dos pressupostos do PARU, e as outras duas idéias perpassam pelos documentos da Comissão Nacional para Reformulação da Educação Superior e do GERES.

A avaliação como prestação de contas e como procedimento de melhoria do desempenho institucional, nos documentos da Comissão Nacional de Reformulação da Educação Superior e do GERES, seria uma contrapartida da

\footnotetext{
14 A Comissão Nacional de Avaliação teve os seguintes membros. Representando a Secretaria de Educação Superior - SESu: Maria José Vieira Féres (Coordenadora), Eda C. B. Machado de Sousa e Paulo Roberto da Silva. Os seguintes representantes de entidades: Hélgio Henrique C. Trindade (Associação Nacional de Instituições Federais de Ensino Superior - Andifes), João Carlos Thomson e José Dias Sobrinho (Associação Brasileira de Universidades Estaduais e Municipais - ABRUEM), Antonio Veronezi (Associação Nacional De Universidades Particulares - ANUP), Ir Norberto Francisco Rauch (Associação Brasileira de Escolas Superiores Católicas - ABESC), Maria Amélia S. Zainko (Fórum dos Pró - Reitores De Graduação), Luiz Carlos Paviu (Fórum Dos Pró-Reitores De Pesquisa E Pós-Graduação), Júlio Wiggers (Fórum dos Pró-Reitores de Extensão) e Wrana M. Panizzi (Fórum dos Pró-Reitores de Planejamento e Administração). Como membros do Comitê Assessor participaram: Dilvo I. Ristoff (UFSC), Eda C. B. Machado de Sousa (SESu/MEC), Fernando Menezes Campello de Souza (UFPe), Heloisa Helena Sant'Anna (UEL), Isaura Belloni (UnB), Jacques Velloso (UnB), Jesus Renato Galo Brunet (UFSM), José Dias Sobrinho (UNICAMP), José Vicente Tavares dos Santos e Denise Balarine Cavalheiro Leite (UFRGS), Lina Cardoso Nunes (UNESA), Marlene Grilo (PUCRS), Victor Meyer (UFSC)
} 
universidade à sociedade que a financia pela autonomia concedida. A Comissão Nacional de Avaliação distanciava-se dessa idéia sem explicitar diretamente uma crítica aos documentos anteriores. A Comissão entendia que a educação seria um bem publico pelo fato de ela afetar toda a sociedade, assim, a universidade presta contas pelo fato de afetar a sociedade e não por ser concedido a ela financiamento e autonomia. É interessante notar que o termo "autonomia", tão caro aos documentos anteriores, não aparece nesse.

O objetivo principal da avaliação do desempenho estaria relacionado com o aperfeiçoamento do projeto acadêmico e social. Dessa forma ter-se-ia a melhoria da qualidade e pertinência das realizações da universidade. Assim, a avaliação seria um ato político e voluntário da instituição. Não foi apresentada a discussão para saber se o processo ocorreria de forma exógena ou endógena. O documento parte do princípio que ela é endógena. A avaliação externa seria solicitada pela própria instituição no sentido de evitar uma ação corporativa e para incorporar a visão de outros cientistas e do cidadão comum.

\subsection{Os princípios fundamentais}

A legitimidade da avaliação, nos documentos anteriores, seria garantida pela comunidade científica (os pares). No documento do PAIUB, a legitimação é dupla: a) política, garantida com a participação e o envolvimento de todos, e b) técnica, manifesta na competência metodológica da sua realização e na fidedignidade dos dados estatísticos ${ }^{15}$.

Os seguintes princípios nortearam a elaboração do PAIUB: 1. Globalidade. 2. Comparabilidade. 3. Respeito à identidade institucional. 4. Não punição ou premiação. 5. Adesão voluntária. 6. Legitimidade. 7. Continuidade (BRASIL, 1993).

Apesar de o documento do PAIUB defender a idéia de que toda avaliação seria institucional, fez-se a opção de iniciar o processo de avaliação pelo ensino de graduação. Escolha justificada pela repercussão que o ensino de graduação tem na sociedade e pelo fato de que a pós-graduação já vinha sendo avaliada por uma agência governamental, a CAPES. Essa opção iria ter uma influência não desejada pelos seus autores, a saber, na política de avaliação como regu-

15 Uma das dificuldades enfrentadas na implantação do PAIUB estava relacionada com a questão da legitimidade. Segundo Joaquim Pinto da Luz, na época, Secretario da Educação Superior (MEC), embora a avaliação institucional fosse consenso, encontrava resistência nas IES: "sua operacionalização esbarrava nos temores da comunidade universitária de que este processo pudesse ser utilizado pelo Governo para desencadear mecanismos de premiação ou punição, com implicações na alocação dos recursos financeiros." (PAIUB, 1993, p. 5), haja vista os fatos antes relatados nesse trabalho. 
lação, implantada no governo Fernando Henrique Cardoso: a avaliação seria dos cursos de graduação e não da instituição.

\subsection{A lógica do documento}

O documento do PAIUB, parte da visão de que a avaliação é um ato político e voluntário da instituição em rever o seu projeto acadêmico e social. $\mathrm{O}$ ato de auto-conhecimento teria função formativa e emancipatória.

\section{Em síntese}

De maneira esquemática o quadro 1 sintetiza os principais aspectos dos três documentos:

\begin{tabular}{|c|c|c|c|c|}
\hline $\begin{array}{l}\text { Documento/ } \\
\text { Tópico }\end{array}$ & $\begin{array}{c}\text { PARU } \\
1983\end{array}$ & $\begin{array}{c}\text { CNRES } \\
1985\end{array}$ & $\begin{array}{c}\text { GERES } \\
1986\end{array}$ & $\begin{array}{l}\text { PAIUB } \\
1993\end{array}$ \\
\hline Autores & $\begin{array}{l}\text { Grupo gestor } \\
\text { (especialistas } \\
\text { em análise de } \\
\text { projetos, sendo } \\
\text { alguns técnicos } \\
\text { do MEC) }\end{array}$ & $\begin{array}{l}24 \text { membros } \\
\text { (heterogêneo) } \\
\text { provenientes } \\
\text { da comunidade } \\
\text { acadêmica e da } \\
\text { sociedade. } \\
\end{array}$ & $\begin{array}{l}\text { Grupo interno } \\
\text { do MEC }\end{array}$ & $\begin{array}{l}\text { Comissão } \\
\text { Nacional de } \\
\text { Avaliação } \\
\text { (Representativa } \\
\text { de entidades) }\end{array}$ \\
\hline Objetivo & $\begin{array}{l}\text { Diagnóstico } \\
\text { da educação } \\
\text { superior }\end{array}$ & $\begin{array}{l}\text { Propor nova política } \\
\text { de educação } \\
\text { superior }\end{array}$ & $\begin{array}{l}\text { Propor nova lei } \\
\text { de educação } \\
\text { superior. }\end{array}$ & $\begin{array}{l}\text { Propor uma } \\
\text { sistemática } \\
\text { de avaliação } \\
\text { institucional. }\end{array}$ \\
\hline $\begin{array}{l}\text { Função/ } \\
\text { Concepção } \\
\text { de avaliação }\end{array}$ & Formativa & Regulação & Regulação & Formativa \\
\hline Justificativa & $\begin{array}{l}\text { Investigação } \\
\text { sistemática da } \\
\text { realidade }\end{array}$ & $\begin{array}{l}\text { Contraponto da } \\
\text { autonomia. } \\
\text { Vincula } \\
\text { financiamento }\end{array}$ & $\begin{array}{l}\text { Contraponto da } \\
\text { autonomia. } \\
\text { Vincula } \\
\text { financiamento }\end{array}$ & $\begin{array}{l}\text { Prestação de } \\
\text { contas por ser } \\
\text { um bem público } \\
\text { que atinge a } \\
\text { sociedade }\end{array}$ \\
\hline $\begin{array}{l}\text { Tipo de } \\
\text { avaliação }\end{array}$ & Interna & Externa & Externa & $\begin{array}{l}\text { Auto-avaliação e } \\
\text { Av. externa }\end{array}$ \\
\hline $\begin{array}{l}\text { Agentes da } \\
\text { avaliação }\end{array}$ & $\begin{array}{l}\text { Comunidade } \\
\text { acadêmica }\end{array}$ & $\begin{array}{l}\text { Conselho Federal de } \\
\text { Educação (para as } \\
\text { universidades) } \\
\text { Universidades (para } \\
\text { as Faculdades } \\
\text { próximas) }\end{array}$ & $\begin{array}{l}\text { Secretaria } \\
\text { de Educação } \\
\text { Superior para a } \\
\text { Ed.pública } \\
\text { Mercado (para a } \\
\text { Ed. Privada) }\end{array}$ & $\begin{array}{l}\text { Endógena e } \\
\text { voluntária }\end{array}$ \\
\hline $\begin{array}{l}\text { Unidade de } \\
\text { análise }\end{array}$ & Instituição & Instituição & Instituição & $\begin{array}{l}\text { Instituição, } \\
\text { iniciando pelo } \\
\text { ensino de } \\
\text { graduação }\end{array}$ \\
\hline Instrumentos & $\begin{array}{l}\text { Indicadores e } \\
\text { Estudo de casos }\end{array}$ & $\begin{array}{l}\text { Indicadores de } \\
\text { desempenho }\end{array}$ & $\begin{array}{l}\text { Indicadores de } \\
\text { desempenho }\end{array}$ & $\begin{array}{l}\text { Indicadores de } \\
\text { desempenho }\end{array}$ \\
\hline
\end{tabular}

Quadro 1: Comparação entre os documentos do PARU/CNRS/GERES/PAIUB. 


\section{Considerações finais}

Tendo como ponto de partida a década de 1980 e o início da década de 1990 , constata-se a existência de duas concepções de avaliação que respondem a duas concepções de educação superior. A primeira delas é conservadora, no sentido de que aceita o proposto pela Reforma Universitária de 1968: a "universidade" como instituição modelo que desenvolve atividades de ensino-pesquisa. Nessa concepção, as propostas do PARU quanto do PAIUB, não questionam a autonomia da instituição e, portanto, a avaliação não está relacionada nem com autonomia nem com financiamento. Nessa concepção, avaliar consiste em pesquisar a instituição para detectar pontos a serem melhorados ou mantidos. A idéia subjacente é formativa, a avaliação é um subsídio para a melhoria da qualidade, por meio da avaliação institucional (PARU) e da avaliação interna (PAIUB).

O relatório da Comissão para a Reformulação da Educação Superior e o documento do GERES apresentam uma proposta de avaliação que está baseada num questionamento do sistema existente. Nos documentos, há forte ênfase na idéia de que a universidade (modelo privilegiado pela reforma universitária de 1968) não seria o único modelo de instituição de educação superior desejável. Então, por ela ser privilegiada com a autonomia, deveria prestar contas das suas atividades, e os recursos financeiros deveriam ser estabelecidos de acordo com os seus resultados. A perspectiva inclui a avaliação externa, inter pares, para garantir resultados mais objetivos.

O GERES foi um grupo executivo, o que, às vezes, no Brasil, se confunde com legislativo e, na sua proposta, não desenvolveu idéias novas, mas selecionou aquelas da Comissão Nacional de Reformulação da Educação Superior que apresentavam e resumiam toda uma concepção de educação superior a da diversificação institucional e da avaliação para alocação de recursos e que iriam guiar as políticas de educação superior da década seguinte. Vale, ainda, destacar que, no documento do GERES, é embrionária a idéia de que a avaliação da educação pública deveria cumprir o mesmo papel que o mercado consumidor de educação tem em relação à educação privada, isto é, controle da qualidade do desempenho institucional.

Já o PAIUB, na seqüência, recupera idéias do PARU, quanto ao foco na instituição e na participação da comunidade acadêmica, retomando a concepção de avaliação como melhoria da qualidade. Diferentemente do PARU, o PAIUB, formulado após os trabalhos da Comissão e do GERES, incorpora alguns elementos indicados por eles para a avaliação das instituições, principalmente, a 
avaliação externa e os indicadores quantitativos que propõe, mas sem por isso, adotar o modelo da diversificação institucional e, muito menos, a intenção de atrelar avaliação com financiamento ou regulação.

Quanto ao papel das agências, o documento da Comissão Nacional de Reformulação da Educação Superior antecipa discussões posteriores (meados da década de 1990) sobre a função do Conselho Federal de Educação, seja ele uma "agência de avaliações", com a função que algumas delas têm em alguns países da América Latina, ou redirecionando parte de suas tarefas para o Ministério da Educação. Também são colocadas alternativas usadas em outros países quanto à acreditação de faculdades isoladas por Universidades.

Nos documentos, há unanimidade de que a avaliação da pós-graduação brasileira realizada pela CAPES seria determinante para a qualidade desse nível educacional. Em nenhum deles, essa avaliação foi colocada em xeque. Mesmo o documento do PAIUB - no qual se defende a avaliação institucional como um processo interno - não a problematiza e nem questiona o fato de ela ser uma avaliação basicamente externa. Os documentos da Comissão Nacional de Reformulação da Educação Superior e do GERES, ainda, apontam que seria exemplar para os outros níveis a prática da avaliação por pares realizada pela agência.

Merece destaque assinalar que, embora o modelo proposto pela Comissão seja a base do que viria a ser a educação superior brasileira a partir de meados da década de 1990, a relação direta entre avaliação e financiamento foi, apenas, parcialmente implantada no Brasil. Ou seja, não se verifica o uso dos resultados da avaliação sistêmica como critérios unívocos e determinantes para a alocação de recursos, apesar de esses resultados serem considerados na aplicação de certas políticas de educação superior, tais como a Gratificação de Estímulo à Docência (GED) nas IFES, o Fundo de Financiamento ao Estudante do Ensino Superior (FIES) e o Programa Universidade para Todos (PRO-UNI) nas IES privadas (AMARAL, 2005) ${ }^{16}$

A análise dos documentos permite detectar tópicos que fizeram parte do desenvolvimento futuro da avaliação da educação superior no Brasil, nas décadas posteriores de 1990 e 2000 . A utilização do mercado com elemento de

16 O autor considera que existe no Brasil vinculação entre avaliação e financiamento na alocação de recursos para as IFES, pois eles estão determinados segundo uma fórmula que considera alguns indicadores de desempenho quantitativos. Com essa lógica, também analisa a GED (Gratificação de Estímulo à docência). Ainda, afirma que os resultados do Provão e do Enade tem conseqüência no financiamento de IES por constituir um dos elementos que habilitam os cursos das instituições privadas para receber alunos beneficiados com o FIES ou oferecer bolsas do PRO-UNI, que implicam Fundo público e renúncia fiscal, respectivamente. 
regulação, insinuada pelo GERES, tomaria forma com a introdução de um instrumento novo ${ }^{17}$ o Exame Nacional de Cursos (BARREYRO, 2004; ROTHEN, 2003). Com esse instrumento somado à Avaliação das Condições de Oferta recupera-se a idéia do PAIUB de iniciar a avaliação pelos cursos de graduação. A partir de 2004, com o Sistema Nacional de Avaliação da Educação Superior (SINAES), tem-se a implantação de uma proposta que, por um lado, recupera a educação superior como um bem público e a centralidade da auto-avaliação, mas, por outro, resgata a idéia da avaliação como referencial para a regulação, assumindo elementos das duas concepções de avaliação e as ressignificando (BARREYRO; ROTHEN, 2006). Mas isso é uma outra história...

\section{Referências}

AMARAL, Nelson Cardoso. A vinculação Avaliação/Financiamento na Educação Superior Brasileira. Impulso, Piracicaba, SP, v. 16, n. 40. p. 81-91, 2005. AMORIM, Antônio. Avaliação institucional da universidade. São Paulo: Cortez, 1992.

BARREYRO, Gladys Beatriz; ROTHEN, José Carlos. SINAES contraditórios: considerações sobre a elaboração e implantação do Sistema Nacional de Avaliação da Educação Superior. Educação \& Sociedade, Campinas, SP, v. 27, n. 96, especial, p. 955-977, 2006.

BARREYRO, Gladys Beatriz. Do Provão ao SINAES: o processo de construção de um novo modelo de avaliação da educação superior. Avaliação, Campinas, SP, v. 9, n. 2, p. 37-49, 2004.

BELLONI, Isaura. Avaliação da universidade: por uma proposta de avaliação conseqüente e compromissada política e cientificamente. In: FÁVERO, Maria de Lourdes (Org.) A universidade em questão. São Paulo: Cortez-Autores Associados, 1989. p. 55-70

BRASIL. MINISTÉRIO DA EDUCAÇÃO E CULTURA. Conselho Federal de Educação. A propósito da qualidade do Ensino Superior no Brasil: anais de dois encontros. Brasília, 1982.

17 O "Provão" - Exame Nacional de Cursos - foi uma prova aplicada aos formandos das Instituições de Educação Superior brasileira entre 1997 e 2003. Seus resultados eram divulgados oficialmente, organizados segundo rankings de instituições que, pela sua vez, utilizavam esses dados para propaganda e concorrência inter-institucional. 
BRASIL. MINISTÉRIO DA EDUCAÇÃO E DO ESPORTO. Secretaria do Ensino Superior. Programa de Avaliação Institucional das Universidades Brasileiras - PAIUB. Brasília, 1993.

CARDOSO, Irene Arruda Ribeiro. A modernização da universidade brasileira e a questão da avaliação. In: MARTINS, Carlos Benedito (Org.) Ensino superior brasileiro. Transformações e perspectivas. São Paulo: Brasiliense, 1989.

COMISSÃO NACIONAL DE REFORMULAÇÃO DA EDUCAÇÃO SUPERIOR. Uma nova política para a educação superior brasileira, 1985. Disponível em: <http://www.schwartzman.org.br/simon/comissao.htm>. Acesso em: 10 out. 2007.

CUNHA, Luiz Antônio. Nova reforma do ensino superior: a lógica reconstruída. Cadernos de Pesquisa, São Paulo, n. 101, p. 20-49, jul. 1997.

GRUPO EXECUTIVO PARA A REFORMULAÇÃO DA EDUCAÇÃO SUPERIOR. RELATÓRIO - GERES. Brasília: Ministério da Educação, 1986 Disponível em: $<$ http://www.schwartzman.org.br/simon/pdf/geres.pdf $>$. Acesso em: jul. 2007.

GRUPO GESTOR DA PESQUISA. Programa de Avaliação da Reforma Universitária. Educação brasileira, Brasília, CRUB, v. 5, n. 10, 1983.

PROGRAMA DE AVALIAÇÃO DA REFORMA UNIVERSITÁRIA-PARU. Revista de Saúde Pública. São Paulo, v. 1, n. 17, 1983. Disponível em: $<$ http://www.scielo.br/scielo.php?pid=S003489101983000400010\&script $=$ sc i_arttext\&tlng=en >. Acesso em: jul. 2007.

ROTHEN, José Carlos. O vestibular do Provão. Avaliação, Campinas, v. 8 n. 1, p. 27-37, 2003.

ROSAS, Paulo. Universidade brasileira: frustrações, expectativas e esperanças. Educação Brasileira, Brasília, v. 7, n. 15, 1985.

SCHWARTZMAN, Simon. Brasil: oportunidade e crise no ensino superior, 1988. Disponível em: <http://www.schwartzman.org.br/simon/pdf/oportun. pdf $>$. Acesso em: jul. 2007.

TEIXEIRA, Mônica (Org.). Universidade e governo: professores da Unicamp no período FHC. São Paulo: Escuta, 2003. 